\title{
Research on the Fatigue Life Prediction Method of Thrust Rod
}

\author{
Guoyu Feng, ${ }^{1,2}$ Wenku Shi, ${ }^{1}$ Henghai Zhang, ${ }^{1,3}$ Qinghua Zu, ${ }^{1}$ Teng Teng, ${ }^{4}$ and Zhiyong Wu ${ }^{5}$ \\ ${ }^{1}$ State Key Laboratory of Automotive Simulation and Control, Jilin University, Changchun 130025, China \\ ${ }^{2}$ Aircraft Control Department, Aviation University Air Force, Changchun 130022, China \\ ${ }^{3}$ School of Automotive Engineering, Shandong Jiaotong University, Jinan 250023, China \\ ${ }^{4}$ China FAW Group Corporation R\&D Center, Changchun 130011, China \\ ${ }^{5}$ Changchun Chengyuan Auto Parts Limited Company, Changchun 130114, China
}

Correspondence should be addressed to Guoyu Feng; wsry1819@sina.com and Wenku Shi; shiwk@jlu.edu.cn

Received 20 June 2016; Accepted 22 September 2016

Academic Editor: Mitsuhiro Okayasu

Copyright (C) 2016 Guoyu Feng et al. This is an open access article distributed under the Creative Commons Attribution License, which permits unrestricted use, distribution, and reproduction in any medium, provided the original work is properly cited.

Purpose of this paper is to investigate the fatigue life prediction method of the thrust rod based on the continuum damage mechanics. The equivalent stress used as damage parameters established rubber fatigue life prediction model. Through the finite element simulation and material test, the model parameters and the fatigue damage dangerous positions were obtained. By equivalent stress life model, uniaxial fatigue life of the V-type thrust rod is analyzed to predict the ratio of life and the life of the test was 1.73, within an acceptable range, and the fatigue damage occurring position and finite element analysis are basically the same. Fatigue life analysis shows that the method is of correct, theoretical, and practical value.

\section{Introduction}

Thrust rod ball joint is a typical multidirectional rubber bearing element, and it is mainly used in quasistatic and fatigue strain environments. In complex work environments, rubbermetal composite ball joint suspension system may suffer from axial, radial, torsion, deflection, and other conditions to the role and impact loading [1-9]. Fatigue failure of the rubber material is one of the main forms of failure cause thrust rod; the thrust rod service life depends primarily on the fatigue life of the rubber ball joints [10-14]. Therefore, the study rubber ball joint fatigue life is the key thrust rod service life analysis.

Studies have shown that the process of rubber dynamic fatigue can be divided into crack initiation and propagation and failure in three stages [15-17]. The first stage is a dramatic change in stress; the material appears to be rubber under stress softening phenomenon; second stage is the slowly varying stress or the internal surface of the rubber material to produce microcracks, often referred to as nuclear damage; third stage microcracks develop into cracks and continuously expand open until the rubber material is completely destroying a fracture phenomenon. The fatigue life of the rubber member is composed mainly of crack initiation life and crack propagation life in two parts [18-21].

MARS research of natural rubber under cyclic loading cracks nucleation, expansion, and ultimate failure studies the relationship between crack growth and crack growth rate of the number of cycles and the energy release rate and summed up the crack growth life under uniaxial loading conditions and strain energy density function formula [22]. Woo and colleagues studied the maximum strain energy density and maximum strain Green rubber amount that are lifetime prediction parameters [23]. Rubber fatigue is a hot area; many scholars have carried out relevant research, but because the fatigue damage mechanism of rubber material is complex, the currently accepted and effective method for the prediction of standard rubber products and the fatigue life is not formed.

The main thrust rod is subjected to low frequency and large load, once the rubber material cracks quickly expand, resulting in fatigue failure; hinge rubber layer and the ball were almost wrapped-up metal parts; the initial crack generation position cannot be directly observed or detected. Thus, the fatigue life of the thrust rod crack initiation is life based. 


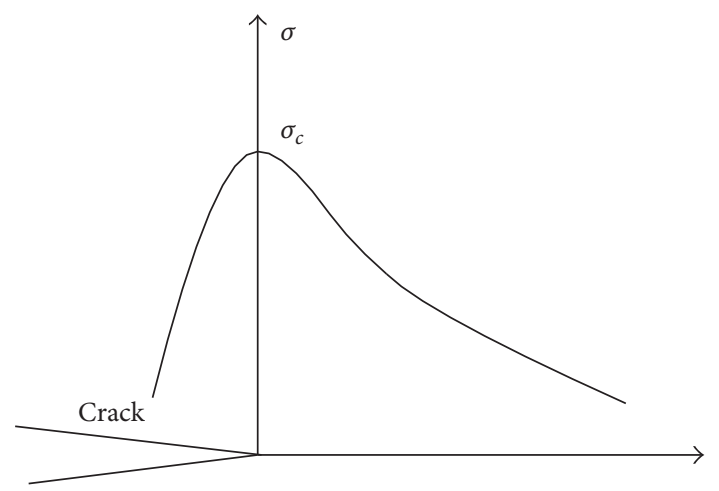

FIGURE 1: Distribution of crack tip stress.

\section{Rubber Fatigue Prediction Theory}

2.1. Rubber Fatigue Failure Mechanism. Rubber fatigue failure is generated during repeated deformation when subjected to the elongation of its local deformation of rubber or stress exceeds the limit stress, and fatigue process starts repeatedly under load, so that the final destruction is reached. The starting point of fatigue failure is due to the rubber surface or internal homogeneity and internal defects or microcracks resulting in uneven distribution of stress and local stress concentration, causing the molecular chains, causing cracks in the spread and expansion caused by fatigue failure. Especially in the cyclical state of deformation, rubber molecular chain has a chance to relax and has a stress-strain lag angle, resulting in the fact that deformation of the rubber internal residual stress is increasing in the molecular chain always maintaining a certain stress gradient and fracturing more easily. Because of the fatigue failure, first at a certain point it produces tiny cracks; its starting point is called "fatigue source" and a source of fatigue crack from the beginning and gradually extended to four weeks.

Deformation of rubber is generally limited deformation, fatigue with the development process, and the first increase in tensile strength, after the maximum value tends to decrease. After the element cracks within a small area from the opposite direction near the beginning of the crack tip, the stress increases, increasing rigidity and maximum stress at the crack tip; this value is known as the cohesive strength, and then stress is reduced [24]. Crack tip stress distribution is shown in Figure 1 [25].

From the energy point of view, to overcome the stress fracture that is acting, we will expand the crack extension. And after cracks tear strength, dynamic modulus of elasticity and the loss factor is reduced at first, after a minimum turn increases, and the rubber in an external energy can continue this form of stress relaxation to be absorbed. Both for uniaxial loading and for multiaxial loading, the crack positions the main subject of the maximum principal stress directions. When tension crack propagation direction is simple, the direction of the maximum principal stress is perpendicular. When the maximum principal stress is greater than the critical stress, the material damage will occur, and the carrying capacity decreases [25].
2.2. Fatigue Life Prediction Model. Strain equivalence hypothesizes that the deformation stress acting on the material damage caused by the deformation is equivalent to the role of virtual nonmaterial damage for a one-dimensional problem; this principle is expressed as

$$
\varepsilon=\frac{\sigma}{E}=\frac{\widetilde{\sigma}}{\widetilde{E}}
$$

Formula: $\varepsilon$ is strain; $\sigma$ is nominal stress; $\widetilde{\sigma}$ is a cross section on the effective stress; $E$ is lossless elastic modulus; $\widetilde{E}$ is the elastic modulus of the material damage.

Based on the principle of equivalent stress, Lemaitre and Chaboche proposed damaged material constitutive equation, the nominal stress tensor and effective stress tensor $\sigma$. Damage $\widetilde{\sigma}$ has a relation [26],

$$
D=1-\frac{\sigma}{\widetilde{\sigma}} .
$$

Formula: $D$ is a damage factor; there is no material damage when the initial damage factor is 0 and when the value is 1 damage to the formation of cracks occurs.

When using a second class Piola Kirchhoff stress, according to the theory of finite strain and Lagrange, formula (2) can be expressed as

$$
D=1-\frac{\sigma_{i}}{\widetilde{\sigma}_{i}}
$$

Formula: $\sigma_{i}$ is the current principal stress direction $i$; $\widetilde{\sigma}_{i}$ is effective principal stress.

Research shows that the calculation method of the rubber material equivalent stress is as follows [27]:

$$
\sigma_{f}=\sqrt{\sigma_{1}^{2}+A \sigma_{2}^{2}+B \sigma_{3}^{2}} .
$$

Formula: $\sigma_{f}$ is equivalent force; $\sigma_{1}, \sigma_{2}, \sigma_{3}$ are for the three directions of principal stress.

$$
\begin{gathered}
\sigma_{1}>0, \quad \sigma_{1} \geq \sigma_{2} \geq \sigma_{3}, \\
A= \begin{cases}1, & \sigma_{2}>0 \\
0, & \sigma_{2} \leq 0,\end{cases} \\
B= \begin{cases}1, & \sigma_{3}>0 \\
0, & \sigma_{3} \leq 0 .\end{cases}
\end{gathered}
$$

When the principal stress is greater than zero, it is assumed that not only tensile stress crack initiation and propagation of rubber contribute to crack closure, but also stress does, and thus they do not contribute to crack initiation and propagation.

We use effective stress parameters to assess the fatigue life of rubber parts, complex stress state, its geometry, and loading conditions unrelated to better reflect the actual situation of the fatigue life. This paper uses the equivalent stress as the fatigue damage parameter.

Based on continuum mechanics, assuming that the rubber material is isotropic strain energy function describes the 
characteristics of rubber elasticity by unit volume. For Ogden model, the strain energy per unit volume is a function of [28]

$$
U=\sum_{i=1}^{N} \frac{2 \mu_{i}}{\alpha_{i}^{2}}\left(\bar{\lambda}_{1}^{\alpha_{i}}+\bar{\lambda}_{2}^{\alpha_{i}}+\bar{\lambda}_{3}^{\alpha_{i}}-3\right)+\sum_{i=1}^{N} \frac{1}{D_{i}}(J-1)^{2 i},
$$

where $N$ is the model order, $\mu_{i}, \alpha_{i}, 1<i<n$ is temperature dependent material parameters, the value is determined by the test data, $D_{i}$ material parameters are determined by the initial bulk modulus, $\lambda_{i}$ is the main rubber elongation ratio, and $J$ is elastic volume ratio, considering the rubber is incompressible, and $J=\lambda_{1} \lambda_{2} \lambda_{3}=1$.

Under uniaxial stress state, $\lambda_{1}=\lambda_{U}, \lambda_{2}=\lambda_{3}=\lambda_{U}{ }^{-1 / 2}$. as [29]

In the state of uniaxial tensile stress $\sigma_{U}$ can be expressed

$$
\sigma_{U}=\frac{\partial U}{\partial \lambda_{U}} .
$$

Formula: $\lambda_{U}$ is a front uniaxial tensile elongation ratio state; $U$ is strain energies.

Under uniaxial stress state, the second-order model is Ogden strain energy function which can be expressed as [30]

$$
U=\sum_{i=1}^{2} \frac{2 \mu_{i}}{\alpha_{i}}\left(\lambda_{U}^{\alpha_{i}}+2 \lambda_{U}^{-\alpha_{i} / 2}-3\right) .
$$

In formulas (8) to (7), the stress can be obtained as expression $\sigma_{U}$ :

$$
\begin{aligned}
\sigma_{U}= & \sum_{i=1}^{2} \frac{2 \mu_{i}}{\alpha_{i}}\left[\lambda_{U}^{\left(\alpha_{i}-1\right)}-\lambda_{U}^{-\left(\alpha_{i} / 2+1\right)}\right] \\
= & \frac{2 \mu_{1}}{\alpha_{1}}\left[\lambda_{U}^{\left(\alpha_{1}-1\right)}-\lambda_{U}^{-\left(\alpha_{1} / 2+1\right)}\right] \\
& +\frac{2 \mu_{2}}{\alpha_{2}}\left[\lambda_{U}^{\left(\alpha_{2}-1\right)}-\lambda_{U}^{-\left(\alpha_{2} / 2+1\right)}\right] .
\end{aligned}
$$

Considering only one-dimensional state, the strain can be expressed as a function of elongation,

$$
\varepsilon_{U}=\lambda_{U}-1 \text {. }
$$

According to (8), (9), and (10) expression for the stress can be derived:

$$
\sigma_{U}=\sum_{i=1}^{2} \frac{2 \mu_{i}}{\alpha_{i}}\left[\left(\varepsilon_{U}+1\right)^{\left(\alpha_{i}+1\right)}-\left(\varepsilon_{U}+1\right)^{-\left(\alpha_{i} / 2+1\right)}\right] .
$$

By stretching rubber samples tested for stress-strain data fitting can be drawn from material constitutive parameters $\mu_{i}, \alpha_{i}$.

Formulas (11) to (2) can be obtained for the damage stress

$$
\widetilde{\sigma}=\sum_{i=1}^{2} \frac{2 \mu_{i}}{\alpha_{i}(1-D)}\left[\left(\varepsilon_{U}+1\right)^{\left(\alpha_{i}+1\right)}-\left(\varepsilon_{U}+1\right)^{-\left(\alpha_{i} / 2+1\right)}\right] .
$$

Formula for damage factor is [31]

$$
\dot{D}=-\frac{\partial \varphi^{*}}{\partial y} \text {. }
$$

In the formula, $\varphi^{*}$ is damage dissipation potential; $y$ is damage strain energy release rate.

Let dissipation potential function be of the form [32]

$$
\varphi^{*}=\frac{b}{a+1}\left(\frac{-y}{b}\right)^{a+1},
$$

where $a, b$ are material constants which can be determined by fatigue tests.

Damage strain energy is a function of stress injury and damage strain energy release rate can be defined as

$$
-y=\frac{\partial U}{\partial D}=\frac{\partial U(\widetilde{\sigma})}{\partial D}=\sum_{i=1}^{3} \frac{\partial U}{\partial \lambda_{i}} \frac{\partial \lambda_{i}}{\partial D} .
$$

By formula (2) the following can be derived:

$$
\frac{\partial \widetilde{\sigma}}{\partial D}=\frac{\sigma}{(1-D)^{2}}=\frac{\partial \widetilde{\sigma}}{\partial \lambda_{i}} \frac{\partial \lambda_{i}}{\partial D} .
$$

It can be further derived that

$$
\frac{\partial \lambda_{i}}{\partial D}=\widetilde{\sigma}\left[(1-D) \frac{\partial \widetilde{\sigma}}{\partial \lambda_{i}}\right]^{-1} .
$$

Under uniaxial stress state, the second-order Ogden model consists of (16) and (17) can obtain damage strain energy release rate which can be expressed as

$$
\begin{aligned}
-y & =\frac{\partial U(\widetilde{\sigma})}{\partial D}=\frac{2 \mu_{1}}{\alpha_{1}(1-D)^{2}} \\
& \cdot \frac{\left[\lambda_{U}^{\alpha_{1}-1}-\lambda_{U}^{-\left(\alpha_{1} / 2+1\right)}\right]^{2}}{\left[\left(\alpha_{1}-1\right) \lambda_{U}^{\alpha_{1}-2}+\left(\alpha_{1} / 2+1\right) \lambda_{U}^{-\left(\alpha_{1} / 2+2\right)}\right]} \\
& +\frac{2 \mu_{2}}{\alpha_{2}(1-D)^{2}} \\
& \cdot \frac{\left[\lambda_{U}^{\alpha_{2}-1}-\lambda_{U}^{-\left(\alpha_{2} / 2+1\right)}\right]^{2}}{\left[\left(\alpha_{2}-1\right) \lambda_{U}^{\alpha_{2}-2}+\left(\alpha_{2} / 2+1\right) \lambda_{U}^{-\left(\alpha_{2} / 2+2\right)}\right]} .
\end{aligned}
$$

Under uniaxial loading, effective stress injury is $\sigma_{f}$; then by damage factor (2), (8), (13), (14), and (18) can be derived:

$$
\dot{D}=\left[\frac{\sigma_{f}}{b(1-D)}\right]^{a} .
$$

Under a single cyclic loading, fatigue damage equivalent stress mainly consists of the scope and magnitude of maximum stress, strain amplitude being related.

From this, the next single cycle fatigue damage can be expressed as

$$
\frac{\partial D}{\partial N}=\left[\frac{\sigma_{f}}{b(1-D)}\right]^{a},
$$

where $N$ is the cycle. Formula (20) is obtained by integrating both sides

$$
\int_{0}^{D}(1-D)^{a} d D=\int_{0}^{N_{f}}\left[\sigma_{f} b^{-1}\right]^{a} d N .
$$


TABLE 1: Ogden second-order model fitting parameters.

\begin{tabular}{cccc}
\hline$i$ & $\mu_{i}$ & $\alpha_{i}$ & $D_{i}$ \\
\hline 1 & 0.0009 & 13.1737 & 0.01759 \\
2 & 2.2885 & -3.1471 & 0 \\
\hline
\end{tabular}

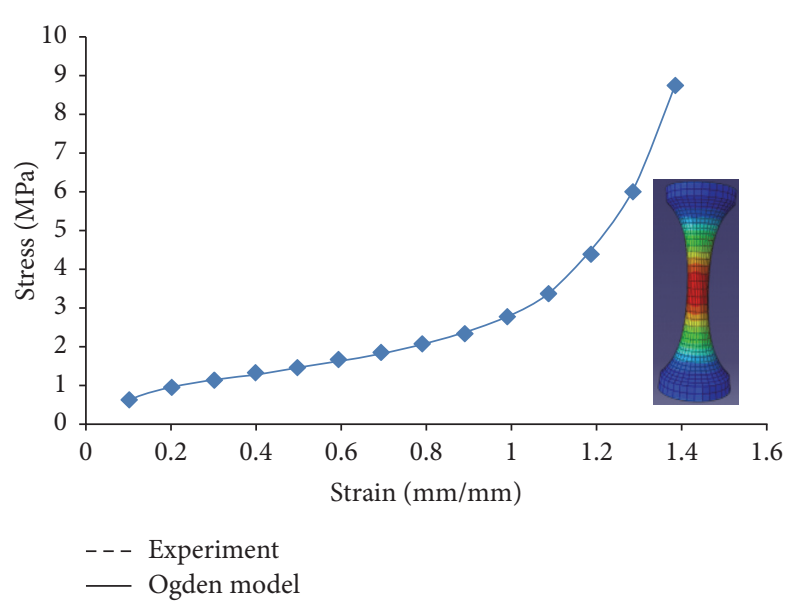

FIGURE 2: Rubber material tensile stress-strain.

Using the initial condition $(N=0, D=0)$ and destroying the conditions $\left(N=N_{f}, D=1\right)$, integral to obtaining the fatigue life expression,

$$
N_{f}=\frac{b^{a}}{1+a} \sigma_{f}^{-a} .
$$

\section{Thrust Rod Finite Element Analysis}

In order to obtain the equivalent stress and fatigue crack location, the finite element method is used to simulate the thrust rod, combined with rubber material specimen testing to verify stress calculations and then the fatigue life prediction.

3.1. Rubber Material Model. In order to obtain the constitutive properties thrust rod rubber material, project partners in accordance with national standards GB/T528-1998 vulcanized rubber or thermoplastic rubber tensile stress-strain properties using dumbbell specimen uniaxial tensile test. Rubber sample during a tensile test at room temperature is used to obtain a stress-strain curve, as shown in Figure 2.

Using ABAQUS software least squares fit function, the experimental data for the stress-strain curve are compared with several models, as shown in Figure 3. Being only under uniaxial test data, second- order Ogden model can better reflect the mechanical response of the loading condition of the rubber material and the experimental data better. So choose second-order Ogden model as rubber constitutive model, model parameters obtained as shown in Table 1.

3.2. Finite Element Modeling Thrust Rod. The main thrust rod is comprised of a ball, ball joints, and sleeve. Spherical hinge has two stub ends; on both sides of the cover, the rubber body,

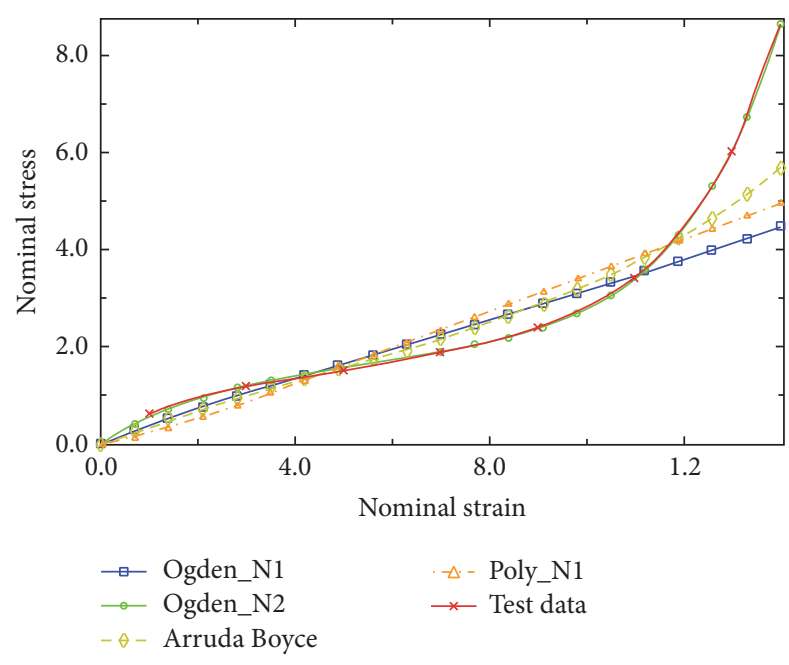

FIGURE 3: Rubber material model.

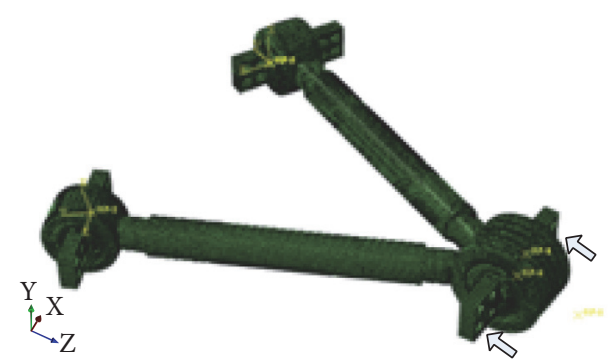

FIGURE 4: V-type thrust rod finite element model.

the plastic layer, and the mandrel five are partially vulcanized together, wherein the rubber layer vulcanized under the load, the deformation by vibration and impact energy absorption part have complex loads; deformation is easily damaged element. Therefore, thrust rod life depends mainly on the fatigue life of the rubber body. When the meshing of rubber and plastic part is $\mathrm{C} 3 \mathrm{D} 8 \mathrm{H}$ unit, plastic layer material density is $1.2 \times 10^{-6} \mathrm{~kg} / \mathrm{mm}^{3}$, Poisson's ratio is 0.40 , and a modulus of elasticity is $1384 \mathrm{~N} / \mathrm{mm}^{2}$. Metal materials used are C3D8R unit, density of $7.8 \times 10^{-6} \mathrm{~kg} / \mathrm{mm}^{3}$, Poisson's ratio of 0.30 , and an elastic modulus of $2.10 \times 10^{5} \mathrm{~N} / \mathrm{mm}^{2}$. Thrust rod big end ball joint screw mandrel has $150 \mathrm{kN}$ applied load; two small ball joint spindle fixed constraints were applied to extract data center reference point. V-type thrust rod finite element model is shown in Figure 4.

Ball joints in the radial load and deformation of rubber are shown in Figure 5. One side of the rubber will produce compressive deformation (A location), while the other side will produce the tensile deformation of the rubber (B location). Because of the incompressible rubber characteristics, the area of the free end of the compression side rubber will expand outwardly and cause nearby rubber tensile deformation. If the compression is too large and rubber vulcanization of the mandrel and the expansion of the free surface at the end of the tensile stress happen, the other side of the rubber tension will produce tensile stress; tensile stress 


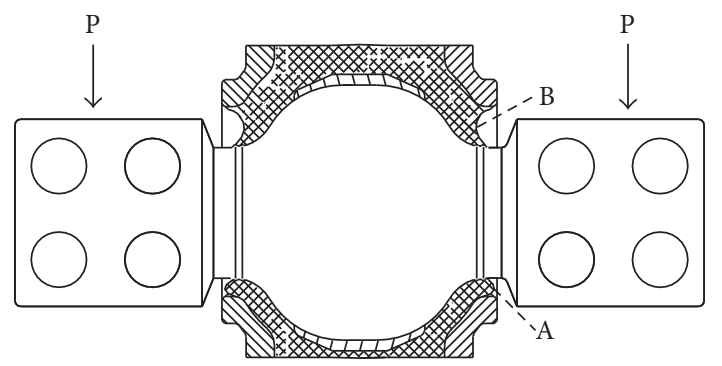

FIGURE 5: The radial loads by deformation of rubber ball joints schematic.

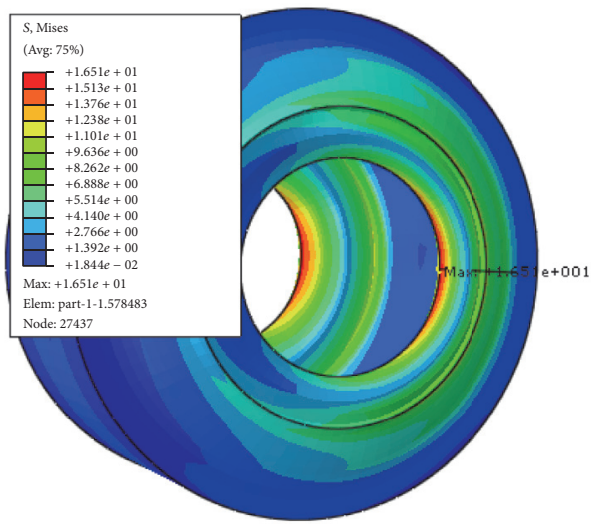

FiguRE 6: The rubber layer maximum stress.

is caused by rubber and metal bonded face of the plastic and rubber cracking and accelerates the aging of the main factors of rubber.

To improve the fatigue resistance of the rubber certain precompression is carried out to reduce or even eliminate the tensile deformation caused by the radial load. Between the rubber body and the outer part, $2 \mathrm{~mm}$ and $5 \mathrm{~mm}$, respectively, precompression are in radial and axial directions. Extraction of stress after assembly rubber strain distribution was done to analyze the performance of the original rubber bushing. Big-end rubber calculated maximum tensile principal stress is $13.86 \mathrm{Mpa}$ and plastic maximum tensile principal stress is $6.861 \mathrm{Mpa}$, which are within the allowable range of stress.

3.3. Finite Element Results. Applying longitudinal load of $150 \mathrm{kN}$ ball joints on both sides of the big end of the mandrel thrust rod, the rubber layer results obtained are shown in Figures 6 and 7 .

Finite element analysis results show that the longitudinal loading and fatigue failure occur in first location; cloud colour shows the deep region; the fatigue test results also validate the fact that the region is a dangerous area; first fatigue cracks easily. The maximum number of principal strains calculated value of 0.809 . Extracting three directions of hazardous area rubber units of the main stress by formula (4) and (5) the calculated equivalent stress is as shown in Table 2.

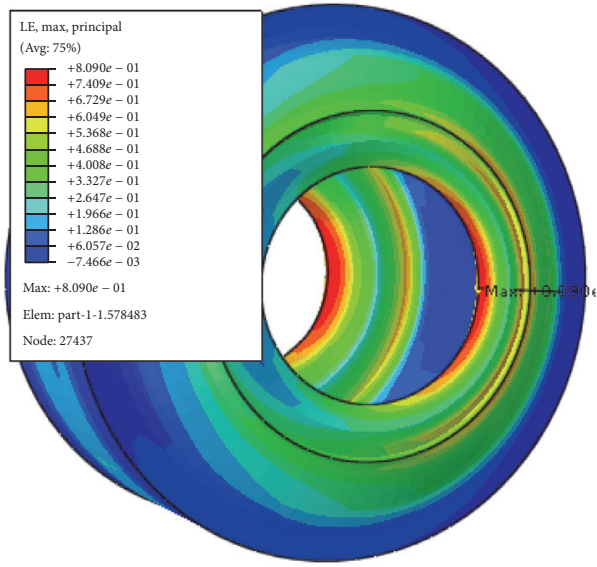

FIGURE 7: Rubber layer maximum logarithmic strain.

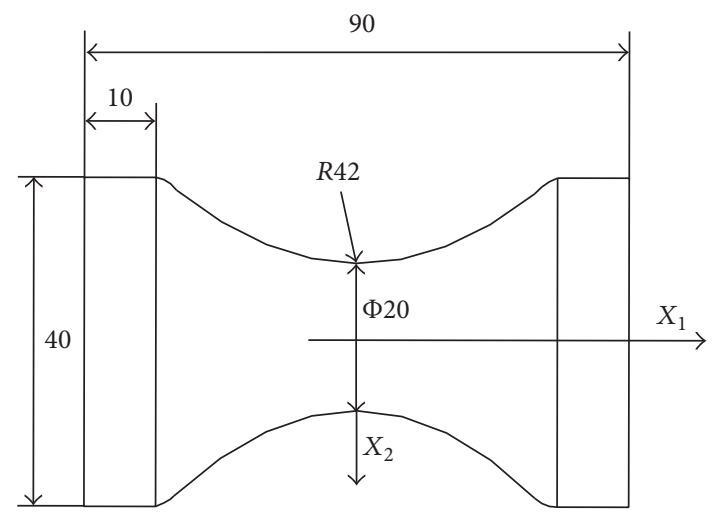

Figure 8: Rubber dumbbell specimens.

TABLE 2: Equivalent stress hazardous areas.

\begin{tabular}{lcccc}
\hline Unit number & $\sigma_{1}$ & $\sigma_{2}$ & $\sigma_{3}$ & $\sigma_{f}$ \\
\hline 578978 & 14.071 & 4.911 & 4.205 & 15.485 \\
578759 & 8.542 & 2.482 & 0.554 & 8.913 \\
578724 & 12.265 & 7.247 & 8.013 & 16.345 \\
578754 & 8.189 & 3.050 & 4.066 & 9.638 \\
563230 & 11.832 & 10.219 & 9.156 & 18.118 \\
\hline
\end{tabular}

\section{Life Prediction and Verification}

4.1. Fatigue Life Prediction. Rubber thrust rod element is according to the fatigue life of the life of the rubber dumbbell specimens to predict dumbbell test piece of rubber as shown in Figure 8. The displacement control is used on hydraulic servo dynamic testing machine for specimen uniaxial tensile fatigue test, sine wave displacement control, and test frequency of $1 \mathrm{~Hz}$. 
For uniform stretching state in the length $L$ of the rubber rod, taking into account the fact that the nearly incompressible rubber material is compressed, the configuration before and after deformation can be described as [33]

$$
\begin{aligned}
& x_{1}=\lambda X_{1}, \\
& x_{2}=\lambda^{-1 / 2} X_{2}, \\
& x_{3}=\lambda^{-1 / 2} X_{3},
\end{aligned}
$$

wherein $X_{i}, x_{i}(i=1,2,3)$ were predeformed position coordinates of a point on the rubber specimen. $\lambda$ is an $X_{1}$ direction elongation, defined as the ratio of the length of the specimen before and after the deformation direction $X_{1}$ of $\lambda=l / L, l$ length after stretching. When the lever tension happens, $\lambda>1$; when the lever compression happens, $0<$ $\lambda<1$.

Axial load being along the rubber specimen, the deformation gradient rubber sheet specimen amount is [33]

$$
\begin{aligned}
F & =\left(\begin{array}{lll}
\frac{\partial x_{1}}{\partial X_{1}} & \frac{\partial x_{1}}{\partial X_{2}} & \frac{\partial x_{1}}{\partial X_{3}} \\
\frac{\partial x_{2}}{\partial X_{1}} & \frac{\partial x_{2}}{\partial X_{2}} & \frac{\partial x_{2}}{\partial X_{3}} \\
\frac{\partial x_{3}}{\partial X_{1}} & \frac{\partial x_{3}}{\partial X_{2}} & \frac{\partial x_{3}}{\partial X_{3}}
\end{array}\right) \\
& =\left(\begin{array}{ccc}
\lambda & 0 & 0 \\
0 & \lambda^{-1 / 2} & 0 \\
0 & 0 & \lambda^{-1 / 2}
\end{array}\right) .
\end{aligned}
$$

Thus, the right Green deformation tensor $C$ and left Green deformation tensor $B$ are equal [33],

$$
B=C=F^{T} F .
$$

Green-Lagrange strain tensor $E$ and Almansi-Euler strain tensor $e$, respectively, by the left and right Green deformation tensors $B$ and $C$ derived.

It follows that

$$
\begin{gathered}
E=\frac{1}{2}(C-I)=\frac{1}{2}\left(\begin{array}{ccc}
\lambda^{2}-1 & 0 & 0 \\
0 & \lambda^{-1}-1 & 0 \\
0 & 0 & \lambda^{-1}-1
\end{array}\right), \\
e=\frac{1}{2}\left(I-B^{-1}\right)=\frac{1}{2}\left(\begin{array}{ccc}
1-\lambda^{-2} & 0 & 0 \\
0 & 1-\lambda & 0 \\
0 & 0 & 1-\lambda
\end{array}\right) .
\end{gathered}
$$

Therefore, their main value is the three elements of the corresponding diagonal tensor.

When the lever is in a stretched condition, $\lambda>1$. According to engineering strain relations with each component of Green-Lagrange strain between the availability axially stretched rubber specimens, the maximum principal engineering strain is

$$
\varepsilon_{E}=\lambda-1
$$

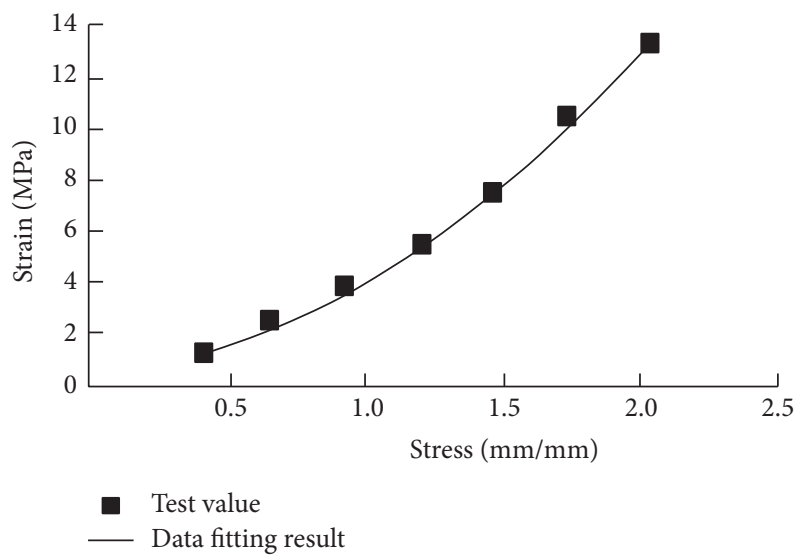

FIGURE 9: Engineering stress and engineering strain relations.

Formula: $E_{11}$ is tensor $E$ elements in the first row and first column, also called the strain tensor components correspondingly.

Logarithmic strain can be seen, and the direction of $X_{1}$ is the biggest main logarithmic strain $\varepsilon_{L}$ [34],

$$
\varepsilon_{L}=\int_{L}^{l} \frac{d l}{l}=\ln \frac{l}{L}=\ln \lambda
$$

Under constant amplitude alternating load, the maximum principal strain and the cycle change over time.

Specimen ball joints rubber engineering stress and engineering strain relationships and effective stress and fatigue life relations are shown in Figures 9 and 10. Test specimens stress and strain data by least squares fitting correlation coefficient $R^{2}$ equals 0.99 , to give power function equation (29).

$$
y=2.45 x^{2}+2.68 x-0.118
$$

By dumbbell tensile fatigue test pieces fitting the data, equivalent stress calculated according to formula (4) and (5) and life prediction equation (22) can obtain injury parameters $a$ and $b$ which are $a=2.83, b=2059 \mathrm{MPa}$. The finite element calculation to obtain the maximum thrust rod rubber logarithmic principal strain 0.809 into (28) calculated primary elongation; then the main elongation calculated values are substituted into formula (27) which calculated the maximum principal engineering strain by rubber test member of the engineering stress-strain relation (29), corresponding to the calculated stress test. Then the data into the life prediction equation (22) calculated the fatigue life of the thrust rod. Where the stress test is 18.18 , the maximum value and the finite element equivalent stress are 18.118, and the error has $0.3 \%$ more consistent results, suggesting that the finite element calculation results are accurate, so you can use the finite element calculation results which were thrust rod life prediction. Calculate the predicted fatigue life of the thrust rod being 171,394 times numbered 563,230 units.

4.2. Fatigue Test. Thrust rod specimen bench life on the electrohydraulic servo fatigue test system applied $150 \mathrm{kN}$ 


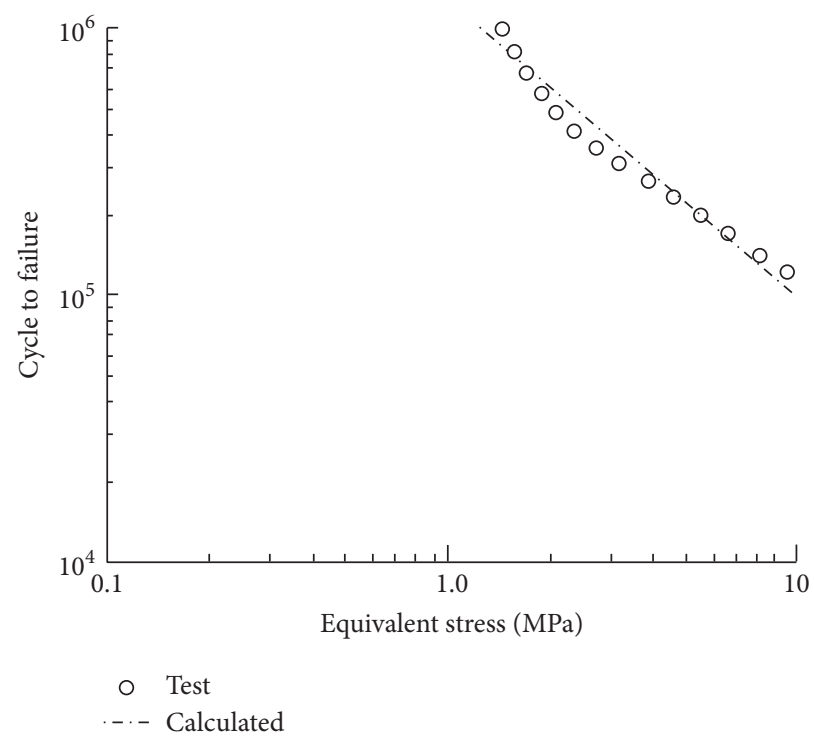

FIgURE 10: Equivalent stress and life curve of dumbbell specimen.
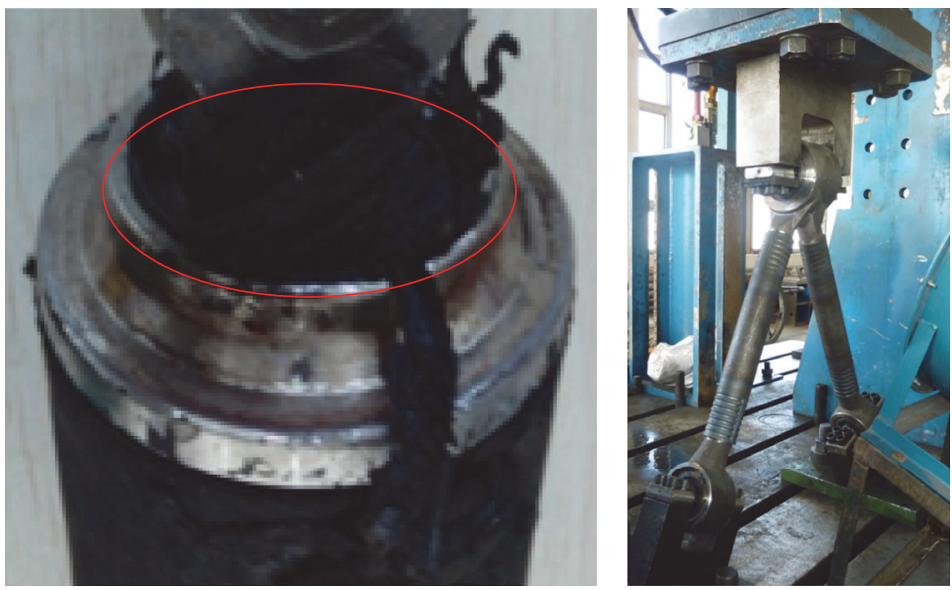

FIGURE 11: Extruded fail of rubber ball joints.

vertical alternating load on the specimen for the sine wave loading, loading frequency of $1 \mathrm{~Hz}$, to maintain the test temperature by cooling fan around $25^{\circ} \mathrm{C}$. In cycle alternating loads, the thrust rod stiffness reduced stiffness by $30 \%$ that is considered failed.

By observing the rod fatigue test we found that, under cyclic loading, thrust rod big end ball joint rubber body and the metal core bond area near the first wrinkles increase fatigue cycles between the mandrel and the end cap and extruded rubber body phenomenon began to appear, gradually to the accumulation to both sides along the circumference, after the completion of 296,500 times of fatigue cycles of products in the form of a broken ring shown in Figure 11.

Appearing near the rubber body bonded with the mandrel significant rubber extrusion, the ball joints are cut; its internal structure is shown in Figure 12. Fatigue should be a source of rubber and metal curing adhesive (shown in the red), and fatigue damage is consistent with the location of the finite element analysis.

The life expectancy is less than the thrust rod specimen measured fatigue life, which may have greater fatigue damage associated with the selected parameters; test life and life expectancy ratio is 1.73 , and the fatigue life prediction in the range of 2 times the measured fatigue life prediction effect is more ideal. Factors that affect the life prediction results are geometric material constant fatigue prediction models obtained through fitting test and parameter fitting method used (there is a certain effect on prediction accuracy); prediction model for the damage equivalent stress range parameters calculated from the engineering stress and engineering strain verification, equivalent stress-dependent finite element results, and thus the accuracy of the finite element analysis also affect the life of the predicted value. 


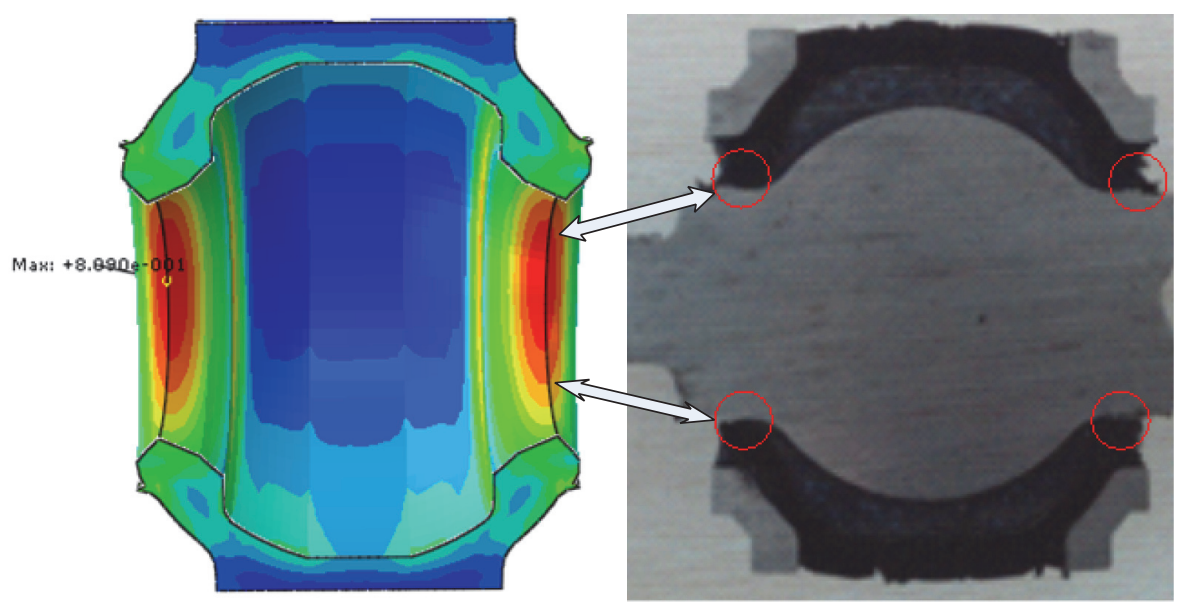

FIGURE 12: Rubber fatigue failure location.

\section{Conclusion}

The theoretical equation for prediction fatigue life of rubber is established based on the equivalent stress. Continuum damage mechanics method can be used to predict fatigue life. The predicted life and experimental data have strong correlation. This supports the idea that the equivalent stress model based on continuum damage mechanics can be applied to study fatigue life for the thrust rod.

\section{Competing Interests}

The authors declare that there is no conflict of interests regarding the publication of this paper.

\section{Acknowledgments}

The authors would like to thank the College of Automotive Engineering, Jilin University, Changchun, Jilin, China, as well as the Jilin Province Major Science and Technology Funded Project (Grant no. 212E362415), and Jilin Province Science and Technology Development Program (Grant no. 20150307034GX).

\section{References}

[1] W. Shi, J. Ke, Q. Wang et al., "Limit load analysis and spherical hinge structure optimization for V-type thrust rod," Journal of Xian Jiaotong University, vol. 47, no. 10, pp. 132-136, 2013.

[2] S. Hu and J. Song, "Design and check of thrust bar in heavy truck," Special Purpose Vehicle, vol. 2, pp. 78-79, 2012.

[3] Z. Changjiang and T. Zhigang, "Optimization design and analysis of commercial vehicle thrust rod," Tech. Rep. SAEC2010P105(2010)17-23, 2010.

[4] J. U. Gang, "Design match of thrust rod in heavy engineering truck," Specia Purpose Vehicile, vol. 2, pp. 74-77, 2012.

[5] D. G. Thomas and M. K. Steven, "Characterizing the roaddamaging dynamics of truck tandem suspensions," SAE Technical Paper 2009-01-1221, 2009.
[6] W. Ma, S. Luo, and R. Song, "Abnormal vertical dynamic performance of subway vehicles," Chinese Journal of Mechanical Engineering (English Edition), vol. 23, no. 2, pp. 174-179, 2010.

[7] P. Sindgikar, N. Jadhav, and K. Gopalakrishna, "Design of cabin suspension characteristics of heavy commercial vehicle," SAE Technical Paper 2008-01-0265, 2008.

[8] J. Li, Z. Zhe, Y. Zhu, and Z. Jie, "Modeling and simulation of the guide rod tandem suspension model," in Proceedings of the International Conference on Electric Information and Control Engineering (ICEICE '11), vol. 1109, pp. 5102-5106, April 2011.

[9] W. Chen, X. Li, X. Chen, and L. Wang, "Middle-high frequency vibration transfer analysis of vehicle suspension and optimization of rubber bushings," Transactions of the Chinese Society for Agricultural Machinery, vol. 42, no. 10, pp. 25-29, 2011.

[10] F. Guosheng, J. Sumei, and Z. Mingjun, "Crack analysis of thrust bar for 55 t heavy dump truck equalizing suspension," Journal of Shijiazhuang Tiedao University(Natural Science), vol. 26, no. 4, pp. 43-46, 2013.

[11] Y. Wang, H. Bai, and J. Hou, "Fatigue damage performance of metal rubber material," Journal of Mechanical Engineering, vol. 47, no. 2, pp. 65-71, 2011.

[12] M. Wang, S. Hao, and C. Li, "Force analysis on traction bar of heavy truck rear suspension based on road load spectrum," Automobile Technology, no. 8, pp. 31-33, 2013.

[13] Y. Hou, "Structure analysis of suspension system V-type rod," Bus \& Coach Technology and Research, vol. 4, pp. 20-22, 2007.

[14] J. Zhang, J. Li, Y. Deng, Y. Huang, and Y. Zhang, "Strength design of thrust bar for $40 \mathrm{t}$ heavy-duty vehicle equalizing suspension," Automobile Technology, no. 3, pp. 19-22, 2008.

[15] X. Wang, W. Shangguan, T. Liu et al., "Experiment of uniaxial tension fatigue and modeling of fatigue life for filled natural rubbers," Journal of Mechanical Engineering, vol. 49, no. 14, pp. 66-73, 2013.

[16] W. V. Mars and A. Fatemi, "Fatigue crack nucleation and growth in filled natural rubber," Fatigue \& Fracture of Engineering Materials and Structures, vol. 26, no. 9, pp. 779-789, 2003.

[17] W. Qian, Structure Optimization and Durability Research of Heavy Commercial Vehicle Thrust Rod, Jilin University, Changchun, China, 2013.

[18] W. Wang, W. Shangguan, X. Duan, and B. Yao, "Study on prediction of fatigue life of rubber mount based on linear cumulative 
fatigue damage theory," Journal of Mechanical Engineering, vol. 48, no. 10, pp. 56-65, 2012.

[19] C.-B. Zhang, "Description of the axial composite rubber ball joint structure with small radial/axial stiffness ratio," Rolling Stock, vol. 48, no. 3, pp. 20-23, 2010.

[20] H. Y. Sun, W. S. Feng, Y. J. Huang, J. G. Rong, and J. X. Liu, "Research on loading characteristics of traction rubber bushing used in high-speed vehicle," Railway Locomotive \& Car, vol. 32, no. 2, pp. 46-48, 2012.

[21] H. Zhang, K. Chen, and J. Zhang, "Static \& dynamis Analysis of V-type," Propelling Rod in Air Suspensnn System, Tractor \& Faun Transporter, vol. 36, no. 3, pp. 40-42, 2009.

[22] W. V. Mars and A. Fatemi, "Fatigue crack nucleation and growth in filled natural rubber," Fatigue and Fracture of Engineering Materials and Structures, vol. 26, no. 9, pp. 779-789, 2003.

[23] C.-S. Woo, W.-D. Kim, and J.-D. Kwon, "A study on the material properties and fatigue life prediction of natural rubber component," Materials Science and Engineering A, vol. 483, no. 1-2, pp. 376-381, 2008.

[24] N. Moës, J. Dolbow, and T. Belytschko, "A finite element method for crack growth without remeshing," International Journal for Numerical Methods in Engineering, vol. 46, no. 1, pp. 131-150, 1999.

[25] G. Chen and L. Chen, "Solution-dependent path crack propagation simulation and its application," Pressure Vessel Technology, vol. 29, no. 10, pp. 36-40, 2012.

[26] J. Lemaitre and J. L. Chaboche, Mechanics of Solid Materials, Cambridge University Press, Cambridge, UK, 1994.

[27] R. K. Luo, P. W. Cook, and W. X. Wu, "Fatigue design of rubber springs used in rail vehicle suspensions," Proceedings of the Institution of Mechanical Engineers, Part F: Journal of Rail and Rapid Transit, vol. 217, no. 3, pp. 237-240, 2003.

[28] Z.-P. Ding, R.-H. Yang, Y.-J. Huang, and J.-L. Bu, "Analysis on the stiffness and fatigue life of variable stiffness rubber bushing," Journal of Vibration and Shock, vol. 33, no. 2, pp. 99-104, 2014.

[29] W. D. Kim, H. J. Lee, J. Y. Kim, and S.-K. Koh, "Fatigue life estimation of an engine rubber mount," International Journal of Fatigue, vol. 26, no. 5, pp. 553-560, 2004.

[30] R. W. Ogden, "Large deformation isotropic elasticity: on the correlation of theory and experiment for incompressible rubberlike solids," Proceedings of the Royal Society of London A: Mathematical A, vol. 326, no. 1567, pp. 565-584, 1972.

[31] G. Ayoub, M. Naït-Abdelaziz, F. Zaïri, J. M. Gloaguen, and P. Charrier, "Fatigue life prediction of rubber-like materials under multiaxial loading using a continuum damage mechanics approach: effects of two-blocks loading and R ratio," Mechanics of Materials, vol. 52, no. 3, pp. 87-102, 2012.

[32] A. Ali, M. Hosseini, and B. Sahari, "Continuum damage mechanics modeling for fatigue life of elastomeric materials," International Journal of Structural Integrity, vol. 1, no. 1, pp. 6372, 2010.

[33] J. Bonet and R. D. Wood, Nonlinear Continuum Mechanics for Finite Element Analysis, Cambridge University Press, Cambridge, UK, 1997.

[34] N. Saintier, G. Cailletaud, and R. Piques, "Multiaxial fatigue life prediction for a natural rubber," International Journal of Fatigue, vol. 28 , no. 5-6, pp. 530-539, 2006. 


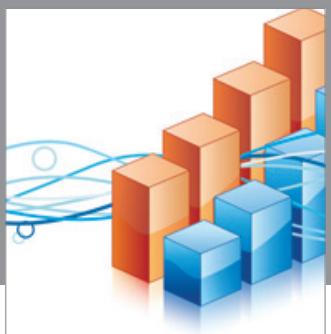

Advances in

Operations Research

vatem alat4

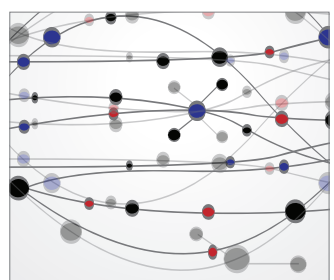

\section{The Scientific} World Journal
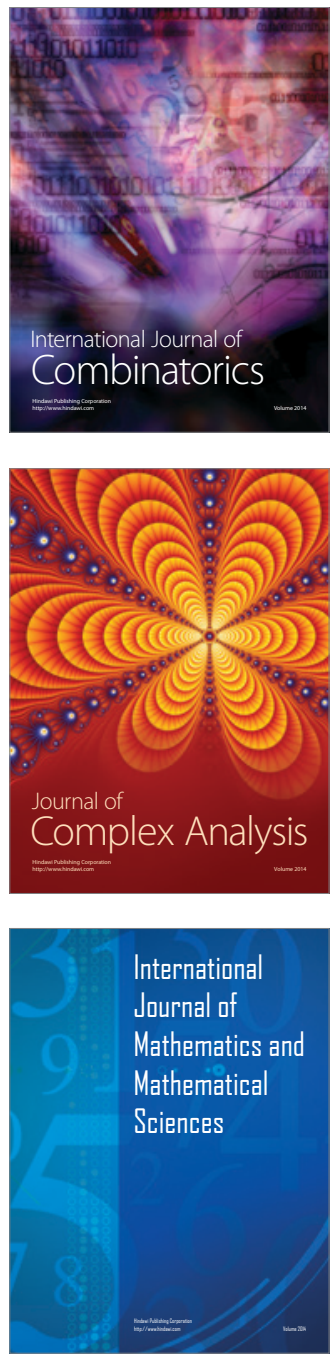
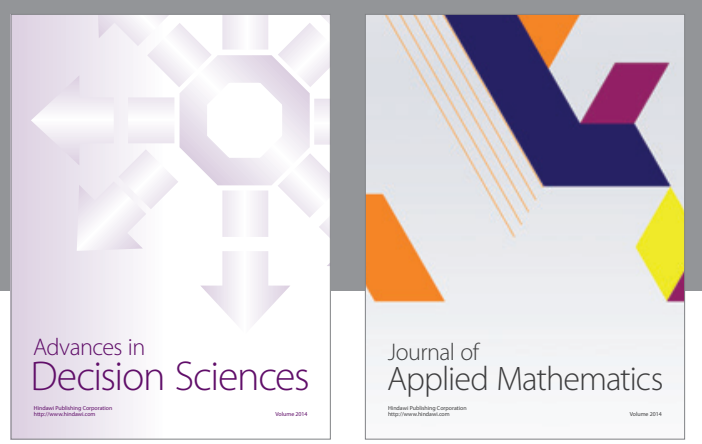

Algebra

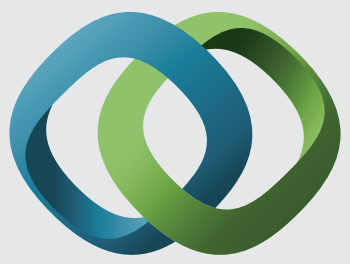

\section{Hindawi}

Submit your manuscripts at

http://www.hindawi.com
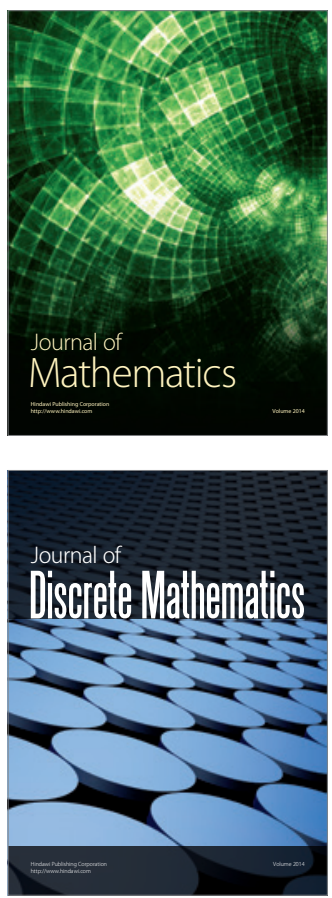

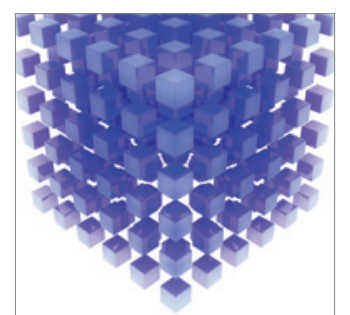

Mathematical Problems in Engineering
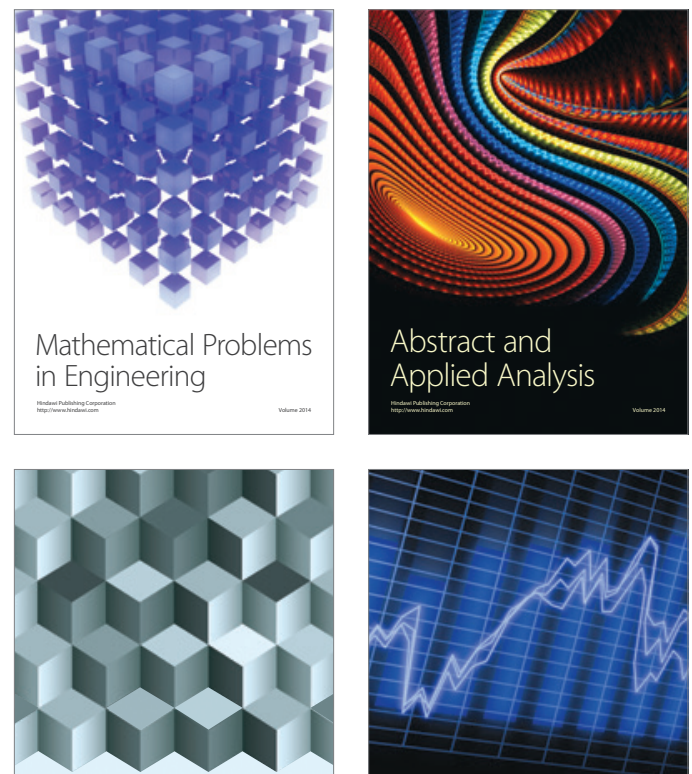

Journal of

Function Spaces

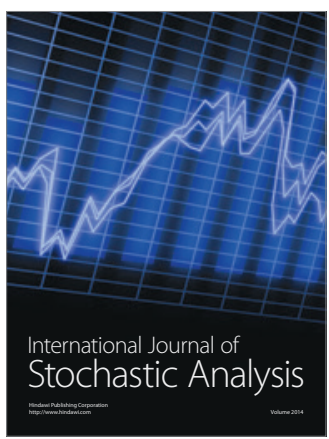

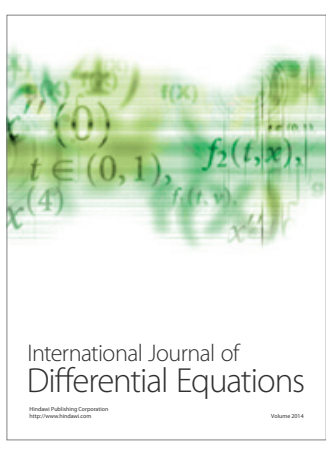
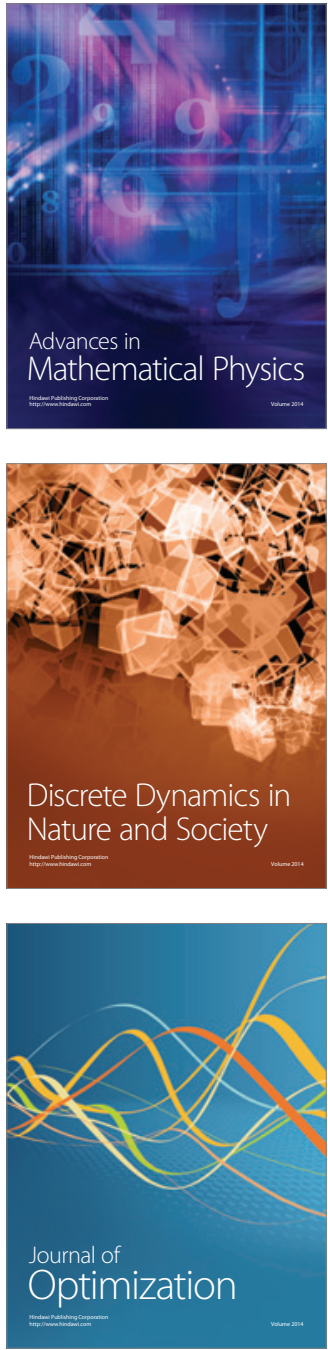